\title{
Access to Mental Health Treatment by English Language Proficiency and Race/Ethnicity
}

\author{
Tetine Sentell, $P h D^{7}$, Martha Shumway, $P h D^{7}$, and Lonnie Snowden, $P h D^{2}$ \\ 'Department of Psychiatry, University of California, San Francisco, San Francisco, CA, USA; ${ }^{2}$ School of Social Welfare, University of California, \\ Berkeley, USA.
}

BACKGROUND: Limited English proficiency (LEP) may contribute to mental health care disparities, yet empirical data are limited.

OBJECTIVE: To quantify the language barriers to mental health care by race/ethnicity using a direct measure of LEP is the objective of the study.

DESIGN: Cross-sectional analysis of the 2001 California Health Interview Survey is the study's design.

PARTICIPANTS: Adults aged 18 to 64 who provided language data $(n=41,984)$ were the participants of the study.

MEASUREMENT: Participants were categorized into three groups by self-reported English proficiency and language spoken at home: (1) English-speaking only, (2) Bilingual, and (3) Non-English speaking. Mental health treatment was measured by self-reported use of mental health services by those reporting a mental health need.

RESULTS: Non-English speaking individuals had lower odds of receiving needed services (OR: 0.28; 95\% CI: 0.17 0.48) than those who only spoke English, when other factors were controlled. The relationship was even more dramatic within racial/ethnic groups: non-English speaking Asian/PIs (OR=0.15; 95\% CI: 0.30-0.81) and nonEnglish speaking Latinos (OR: 0.19; 95\% CI: 0.09-0.39) had significantly lower odds of receiving services compared to Asian/PIs and Latinos who spoke only English.

CONCLUSIONS: LEP is associated with lower use of mental health care. Since LEP is concentrated among Asian/PIs and Latinos, it appears to contribute to racial/ethnic disparities in mental health care. Heightened attention to LEP is warranted in both mental health practice and policy.

KEY WORDS: limited English proficiency; health disparities;

mental health.

J Gen Intern Med 22(Suppl 2):289-93

DOI: $10.1007 / \mathrm{s} 11606-007-0345-7$

(C) Society of General Internal Medicine 2007

\section{INTRODUCTION}

Language barriers have been documented in numerous facets of health care. ${ }^{1}$ Despite a widespread assumption that limited English proficiency (LEP) plays an important role in racial/ ethnic mental health inequalities, ${ }^{2,3}$ surprisingly little empirical research has directly examined these relationships (Snowden, et al. manuscript under review).

Language barriers may be particularly problematic in mental health care because much of mental health diagnosis and treatment relies on direct communication rather than objective tests or medication. Treatment disparities contribute to the disproportionately high disability burden borne by minority communities, ${ }^{3}$ and unnecessary suffering and loss of economic productivity. ${ }^{2}$ Studying English proficiency more directly can shed new light on our understanding of differences in receipt of services by race and ethnicity.

This issue is of particular importance to primary care providers because research has found that the majority of primary care patients believe it is important to receive help from their physician for their emotional distress. ${ }^{4}$ Members of minority racial/ethnic groups are particularly likely to seek help for mental health problems from primary care providers, ${ }^{5-9}$ yet the mental health concerns of minority patients are more likely to go unnoticed in primary care. ${ }^{9}$ Language barriers may make it particularly difficult for primary care providers to meet patients' mental health needs.

Two racial/ethnic groups in the United States are particularly impacted by LEP-Latinos and Asian/Pacific Islanders. One of the few existing studies to quantify the language barrier to mental health care among Latinos found that although Latinos, in general, are significantly less likely than whites to seek care, English-speaking Latinos have access patterns similar to non-Hispanic whites, while Spanish-speaking Latinos are considerably less likely to receive treatment. ${ }^{10}$ Interestingly, this previous study may have underestimated the impact of LEP on access to mental health care as it only included insured individuals, and LEP and associated factors, such as immigration status, can be important barriers to obtaining health insurance. The present study includes both insured and uninsured individuals. Other previous studies have found that factors such as U.S. nativity ${ }^{5}$ and greater acculturation $^{11}$ are associated with greater use of mental health services among Latinos. Although acculturation and nativity are associated with English language proficiency, previous studies were not able to separate their influences because they have not typically included measures of English language proficiency. The present study includes separate measures of English language proficiency, U.S. nativity, and length of time in the United States.

LEP is presumed to keep many Asians and Pacific Islanders from receiving adequate mental health care. ${ }^{2}$ Several recent studies have considered the impact of both language and immigration-related variables on access to mental health care among Asian/Pacific Islanders. ${ }^{12,13}$ Findings have been mixed, with some researchers reporting an association when U.S. nativity 
and years in the United States are considered, ${ }^{13}$ and others reporting no association. ${ }^{12}$ The present study adds to the burgeoning knowledge base attempting to disentangle the multiple sources of mental health care disparities, in general, and among different ethnic and racial groups specifically, focusing particular attention on Latino and Asian/Pacific Islander populations.

\section{METHOD}

\section{Subjects}

The 2001 California Health Interview Survey (CHIS) was used for all analyses. Survey methods of the CHIS are described elsewhere. ${ }^{14}$ Briefly, the CHIS was a random-digit-dial telephone survey of 55,428 California households. Approximately $12 \%$ of adult interviews were conducted in languages other than English. ${ }^{15}$ The study sample included all adults aged 18 to 64 who provided valid responses for English language proficiency $(n=41,984)$. Though the effective response rate of the CHIS was $47 \%$, the percentages of racial/ethnic groups were proportionate with Census totals, and health estimates were similar to findings from other statewide surveys. ${ }^{16}$

\section{Language Groups}

English Language Proficiency was classified into three categories, according to self-reported responses to questions about English proficiency and language spoken at home ${ }^{17}$ : (1) speaking a language other than English at home, and speaking English "not well or not at all" (no English), (2) speaking a language other than English at home, but reported speaking English "well or very well" (bilingual) and (3) speaking only English at home (English only).

\section{Mental Health Need}

Need for Mental Health Treatment was indicated by a positive response to the following question: "During the last 12 months, did you think you needed help for emotional or mental health problems, such as feeling sad, blue, anxious, or nervous?" By responding affirmatively, respondents indicate both that they experienced mental health problems and that they felt they needed "help" in dealing with their problems. Asking respondents to indicate directly a need for help is valuable because it taps personal acknowledgment of need rather than need inferred from reported distress, and because it is closer than other approaches to help-seeking behavior itself. However, because respondents can suffer from distress but reject the availability of potentially useful treatment, this is likely a conservative measure of need for mental health services.

\section{Mental Health Service Use}

Mental Health Service Use was defined by the CHIS item: "Not counting overnight stays, emergency room visits, or visits for drug or alcohol problems, in the past 12 months, have you seen a psychiatrist, psychologist, social worker, or counselor for emotional or mental health problems?" Received Needed Services was defined by endorsing Mental Health Service Use only if a need for mental health treatment was reported because if an individual does not personally consider him or herself in need of help, he or she is unlikely to seek services.

\section{Control Variables}

Acculturation is an important consideration in a study of the relationship between LEP and use of mental health services. The CHIS did not include a direct measure of acculturation, ${ }^{11}$ although it did include a number of related factors in addition to LEP. Two variables relating to immigration status were used to capture the influence of acculturation: (1) Born in the United States (Yes, No), and (2) Years living in the United States, which was asked of all respondents who were not born in the United States. The second variable was ordinal (1 year or less, 2-4 years, 5-9 years, 10-14 years, and 15+ years). Individuals born in the United States were scored as 0 in the second variable. ${ }^{18}$ Other variables included in multivariate analyses were dichotomous indicators of living below the poverty level, marital status, gender, living in an urban area, having health insurance, and self-reported health status (excellent/very good/good vs. fair/poor). Other measures were educational attainment (ordinal with ten levels), ${ }^{15}$ and age (continuous). Those who had health insurance were asked if they had mental health insurance. Imputed values for missing poverty variables were included in the public CHIS data file. ${ }^{15}$

\section{Analysis}

For all mental health need and use variables, bivariate and multivariate analyses were conducted for the entire sample and for individual racial/ethnic groups. Due to the large sample sizes, all reported bivariate comparisons and multivariate models are significant at the $p<.05$ level unless otherwise indicated. All analyses were conducted using STATA $9,{ }^{19}$ accounting for the complex sample design by using jackknife replication to compute standard errors and employing CHIS sampling weights to produce accurate population estimates based on Census 2000 population estimates. ${ }^{20}$ All percentages reported herein are weighted.

\section{RESULTS}

Fifty-two percent of the sample was white, 27\% Latino, 10\% Asian, or Pacific Islander, and 6\% African American. Table 1 presents the characteristics of the study sample by English language proficiency. The majority of the $28 \%$ of respondents who were bilingual, and all of the $9 \%$ who did not speak English well, were Latino or Asian/PI. Among Latinos, 22\% spoke only English, 50\% were bilingual, and 28\% did not speak English; among Asians, 23\% spoke only English, 65\% were bilingual, and 12\% did not speak English.

Table 2 provides a breakdown of reported need for services and receipt of mental health services by English language proficiency. Although similar percentages were seen for selfreported need for mental health services by English proficiency, a dramatic difference was seen in the receipt of needed mental services. In the whole sample, $51 \%$ of those who expressed a need for services and spoke only English received them, compared to $8 \%$ of those who did not speak English. Similar percentages were seen among both Latino and Asian/PI subgroups. It is worth noting, however, that even among those who spoke only English, approximately half of those who indicated a need for mental health services did not receive treatment.

Table 3 highlights the significant variables in the multivariate models predicting receipt of needed services. Being unable 


\begin{tabular}{|c|c|c|c|c|}
\hline \multirow[t]{2}{*}{ Characteristics } & \multirow{2}{*}{$\begin{array}{l}\begin{array}{l}\text { English } \\
\text { only }\end{array} \\
n=29,991\end{array}$} & \multirow{2}{*}{$\begin{array}{l}\text { Bilingual } \\
n=9,243\end{array}$} & \multirow{2}{*}{$\begin{array}{l}\text { No } \\
\text { English } \\
n=2,750\end{array}$} & \multirow{2}{*}{$\begin{array}{l}\text { All } \\
n=41,984\end{array}$} \\
\hline & & & & \\
\hline Age (mean, SE) & $40( \pm .07)$ & $36( \pm .15)$ & $37( \pm .22)$ & $38( \pm .01)$ \\
\hline \multicolumn{5}{|l|}{$\operatorname{Race}^{\dagger}(\%)$} \\
\hline White & 74 & 22 & 0 & 52 \\
\hline Black & 8 & 2 & 0 & 6 \\
\hline Asian/PI & 4 & 24 & 14 & 10 \\
\hline Latino & 10 & 49 & 86 & 27 \\
\hline Other & 5 & 3 & 0 & 4 \\
\hline \multicolumn{5}{|c|}{$\begin{array}{l}\text { Nativity/immigration } \\
\text { status (\%) }\end{array}$} \\
\hline Born in the US & 94 & 46 & 0 & 72 \\
\hline$<5$ Years in US & 1 & 11 & 46 & 8 \\
\hline $5+$ Years in US & 5 & 43 & 54 & 20 \\
\hline HS education (\%) & 95 & 91 & 30 & 87 \\
\hline Insured (\%) & 89 & 81 & 50 & 83 \\
\hline $\begin{array}{l}\text { Have MH } \\
\text { insurance (\%) }\end{array}$ & 89 & 80 & 42 & 85 \\
\hline $\begin{array}{l}\text { Under poverty } \\
\text { level (\%) }\end{array}$ & 7 & 13 & 48 & 12 \\
\hline Married (\%) & 54 & 54 & 60 & 54 \\
\hline $\begin{array}{l}\text { Good, very good, } \\
\text { or excellent } \\
\text { health (\%) }\end{array}$ & 89 & 86 & 55 & 85 \\
\hline $\begin{array}{l}\text { Urban } \\
\text { environment (\%) }\end{array}$ & 86 & 92 & 89 & 88 \\
\hline Male (\%) & 49 & 53 & 43 & 50 \\
\hline
\end{tabular}

*Percentages are weighted.

${ }^{\dagger}$ Totals do not equal $100 \%$ due to rounding.

to speak English was associated with lower odds of receiving needed services $(\mathrm{OR}=0.28$; 95\% CI 0.17-0.48), when other factors were controlled. Similar patterns of results were found in separate analyses of the Latino and Asian/PI groups. Wald tests confirmed that model fit was significantly better $(p<.05)$ after the addition of LEP in all three models. Other significant variables predicting lack of receipt of needed services included being African American or Latino, being younger, being married, having less education, living in a nonurban area, and lacking health insurance.

Respondents who reported they had health insurance were also asked if they had mental health insurance. Among those who had mental health coverage, a relationship was seen between limited English language ability and not receiving needed treatment (OR=0.33; 95\% CI 0.16-0.67), similar to the association seen for the entire sample. This relationship was also seen in a separate analysis of the Latino group $(\mathrm{OR}=0.22$; 95\% CI 0.08-0.59), but the relationship between limited English proficiency and not receiving mental health services was not significant among the Asian/PI group, when only those with mental health coverage were considered $(\mathrm{OR}=0.65$; 95\% CI 0.09-4.52).

\section{DISCUSSION}

Using data from a large, statewide survey, we found that LEP individuals in California were less likely to receive needed mental health services compared to those who spoke English when race/ethnicity and other associated factors, such as poverty, insurance status, U.S. nativity, and length of time in the United States were controlled. Because individuals who do not speak English well in California and elsewhere in the United States are largely concentrated in Asian/PI and Latino racial/ethnic groups, LEP may contribute to racial/ethnic disparities in mental health care.

Targeted examination of LEP within the Asian/PI and Latino subgroups revealed a dramatic difference in receipt of needed mental health care based on English language abilities. In the Asian/PI subgroup, for example, bivariate analyses revealed that 56\% of Asian/PI respondents who spoke only English received needed mental health services, the highest rate of service observed in any subgroup studied. In contrast, only $11 \%$ of Asian/PI respondents who did not speak English received needed services. Similarly, multivariate analyses showed that Asian/PI respondents who did not speak English had $85 \%$ lower odds of receiving treatment compared to those who spoke only English, when other variables were controlled. These findings are consistent with a small, but important area of recent research indicating that studying access to care by race and ethnicity without considering English language proficiency among Latino ${ }^{10}$ and Asian/PI groups ${ }^{13}$ may provide a misleading portrait of access barriers to mental health care.

Our study had several limitations. We only addressed access to treatment. It is important to bear in mind that the receipt of mental health treatment does not guarantee quality of care, which is an important component in successful treatment outcomes. Previous studies have found that racial/ethnic minorities, and those who do not speak English well, generally receive poorer quality mental health care. ${ }^{2}$ However, for all racial/ethnic groups, receiving mental health treatment is associated with better outcomes than receiving no treatment at all. $^{2}$

It is not clear from this study whether differences in service use are due solely to access barriers. Racial and ethnic groups differ in important ways in their desire for mental health services. Our analyses indicate that Asian/Pacific Islanders are less likely than members of other racial/ethnic groups to report a need for mental health services. These results suggest that cultural differences in definitions of mental illness or strategies for dealing with emotional distress may also affect utilization patterns. The lack of a robust measure of clinical need, as opposed to self-identified need, for mental health

Table 2. Need For Mental Health Services and Receipt of Services by English Proficiency and Race/Ethnicity

\begin{tabular}{|c|c|c|}
\hline \multirow[t]{2}{*}{ Variable } & \multirow[t]{2}{*}{$\%$ Need for MH Care } & \multirow{2}{*}{$\begin{array}{l}\text { \% Received Needed Services } \\
\text { Only respondents who } \\
\text { reported a need for MH care }\end{array}$} \\
\hline & & \\
\hline All & 16 & 45 \\
\hline English Only & 18 & 51 \\
\hline Bilingual & 14 & 42 \\
\hline No English & 16 & 8 \\
\hline Latino & 16 & 28 \\
\hline English Only & 17 & 43 \\
\hline Bilingual & 14 & 35 \\
\hline No English & 17 & 8 \\
\hline Asian/PI & 9 & 36 \\
\hline English Only & 11 & 56 \\
\hline Bilingual & 7 & 33 \\
\hline No English & 12 & 11 \\
\hline
\end{tabular}


Table 3. Independent Association of Respondent Characteristics with Receipt of Needed Mental Health Treatment ${ }^{*}$

\begin{tabular}{|c|c|c|c|}
\hline Characteristics & All & Latino & Asian/PI \\
\hline \multicolumn{4}{|c|}{ English proficiency } \\
\hline English only & - & - & - \\
\hline Bilingual & $1.02(0.81-1.28)$ & $0.80(0.53-1.20)$ & $0.44(0.16-1.14)$ \\
\hline No English & $0.28(0.17-0.48)$ & 0.19 (0.09-0.39) & $0.15(0.30-0.81)$ \\
\hline \multicolumn{4}{|l|}{ Race/ethnicity } \\
\hline White & - & - & - \\
\hline Black & 0.62 (0.45-0.85) & - & - \\
\hline Asian/PI & $0.74(0.52-1.06)$ & - & - \\
\hline Latino & $0.70(0.57-0.86)$ & - & - \\
\hline Other races & $0.89(0.64-1.24)$ & - & - \\
\hline \multicolumn{4}{|l|}{ Control variables } \\
\hline Born in US & $2.26(0.99-5.18)$ & $0.67(0.20-2.18)$ & $1.90(0.32-1.37)$ \\
\hline Years in US & $1.10(0.93-1.31)$ & $0.89(0.69-1.13)$ & $1.10(0.79-1.53)$ \\
\hline Insured & 2.04 (1.66-2.50) & $2.38(1.60-3.54)$ & $2.03(0.87-4.73)$ \\
\hline Poverty & $1.23(0.96-1.58)$ & $1.03(0.66-1.62)$ & $1.13(0.40-3.20)$ \\
\hline Age & $1.01(1.00-1.01)$ & $1.02(1.01-1.04)$ & $1.03(1.00-1.06)$ \\
\hline Married & $0.76(0.67-0.86)$ & 0.77 (0.55-1.07) & $0.46(0.22-0.98)$ \\
\hline Good health & $0.86(0.72-1.02)$ & $0.95(0.68-1.31)$ & $2.42(1.20-4.90)$ \\
\hline Education & $1.12(1.08-1.16)$ & $1.14(1.04-1.25)$ & $0.96(0.81-1.14)$ \\
\hline $\begin{array}{l}\text { Urban } \\
\text { environment }\end{array}$ & $1.27(1.07-1.51)$ & $1.17(0.80-1.71)$ & $0.96(0.20-4.50)$ \\
\hline Male & 0.89 (0.77-1.04) & $0.56(0.40-0.79)$ & $0.56(0.26-1.22)$ \\
\hline Unweighted $N$ & 7,790 & 1,569 & 305 \\
\hline
\end{tabular}

*Estimates represent odds ratios (95\% confidence intervals)

services may further obscure this issue in the analyses presented here. Further consideration of these factors may provide additional avenues for reducing disparities in mental health treatment.

Furthermore, LEP itself may not be the critical measure. Instead, it may be a marker for other variables that were unmeasured or not well measured in this study. Acculturation is of particular concern in relation to definitions of mental illness, stigma, and perceptions of mental health care. Without a broader range of specific acculturation measures, it was not possible to completely separate the role of language from other related factors. Interestingly, in multivariate analyses, both proxy measures of acculturation were statistically significant in all three study samples until LEP variables were added, suggesting that English language skills may be responsible for some variation in access to mental health care previously attributed to acculturation when English proficiency was not considered.

This study also confirms that English proficiency is certainly not the only factor leading to mental health disparities. In the analysis including all respondents, race/ethnicity variables were significant even when English language proficiency was included. Many access barriers have been identified as possible contributors to racial/ethnic disparities in receipt of mental health care, such as unequal access to insurance, stigma, racism, discrimination, differences in communication styles, and mistrust and fear of treatment. ${ }^{2}$ Of these variables, only insurance status was controlled in this study. Further study should consider the impact of these variables and how they are associated with LEP.

In the United States, the majority of individuals who do not speak English well are members of racial/ethnic minority groups. As LEP Americans make up a significant, and increasing, portion of the U.S. population, this creates a significant problem for our health system to address. The results of this study have implications for both practice and policy. In the practice setting, extra effort is warranted in primary care settings to explore the mental health needs of patients with limited English proficiency. These patients are particularly likely to seek assistance with mental health problems from primary care providers, yet language barriers may limit discussion of mental health and emotional issues. Furthermore, the limited availability of linguistically appropriate mental health services may make referrals particularly challenging.

In the policy arena, efforts to address health disparities, specifically, as well as more general efforts to increase access to mental health care, should address language barriers. Some policy instruments targeting language barriers are already in place, implemented at the clinic level and beyond. Recent state legislation, such as California's "threshold language policy", ${ }^{21}$ and existing federal laws, particularly Title VI of the Civil Rights Act of $1964,{ }^{22}$ are relevant to this issue. However, the full implications of these laws are not always realized with respect to mental health care. Also, problems exist with the effective implementation of policies concerning language barriers, ranging from lack of awareness about patients' rights to difficulty providing interpreters in all mandated situations for all possible languages. Despite these difficulties, the implementation of policies targeting language barriers to mental health treatment shows promising results. ${ }^{21}$ Such innovative efforts on state, local and clinic levels will hopefully be expanded with the goal of reducing racial/ethnic disparities in mental health care.

Acknowledgements: This work was supported by a California Program on Access to Care grant sponsored by the University of California, Office of the President. Dr. Sentell was supported by a NIMH postdoctoral fellowship during the preparation of this manuscript. Results from this study were presented at the AcademyHealth conference in Boston, MA on June 27, 2005. 
Conflicts of Interest: None disclosed.

Corresponding Author: Tetine Sentell, PhD; Department of Psychiatry, University of California, San Francisco, 2727 Mariposa Street Suite 100, San Francisco, CA 94110, USA (e-mail: tetines@yahoo. com).

\section{REFERENCES}

1. Branch C, Fraser I, Paez K. Crossing the language chasm. Health Affairs. 2005;24:424-34.

2. U.S. Department of Health and Human Services, Mental Health: culture, race, and ethnicity - a supplement to mental health: a report of the Surgeon General. Rockville, MD: US Department of Health and Human Services, Substance Abuse and Mental Health Services Administration, Center for Mental Health Services, 2001.

3. New Freedom Commission on Mental Health, achieving the promise: transforming mental health care in America. Final Report. Rockville, MD, 2003.

4. Brody DS, Khaliq AA, Thompson TL. Patients' perspective on the management of emotional distress in primary care settings. J Gen Intern Med. 1997;12:403-06.

5. Vega WA, Kolody B, Aguilar-Gaxiola S, Catalano R. Gaps in service utilization by Mexican Americans with mental health problems. Am J Psychiatr. 1999;156:928-34.

6. Snowden LR, Pingitore D. Frequency and scope of mental health service delivery to African Americans in primary care. Ment Health Serv Res. 2002;4:123-30.

7. Yeung A, Chang D, Gresham RL Jr, Nierenberg AA, Fava M. Illness beliefs of depressed Chinese American patients in primary care. J Nerv Ment Dis. 2004;4:324-7.

8. Cabassa LJ, Zayas LH, Hansen MC. Latino adults' access to mental health care: a review of epidemiological studies. Adm Policy Ment Health. 2006;3:316-30.

9. Borowsky SJ, Rubenstein LV, Meredith LS et al. Who is at risk of nondetection of mental health problems in primary care? J Gen Intern Med. 2000;15:381-8.
10. Fiscella K, Franks P, Doescher M, Saver B. Disparities in health care by race, ethnicity, and language among the insured: findings from a national sample. Med Care. 2002;40:52-9.

11. Wells KB, Golding JM, Hough RL, Burnam MA, Karno M. Acculturation and the probability of use of health services by Mexican Americans. Health Serv Res. 1989;24:237-57.

12. Abe-Kim J, Takeuchi DT, Hong $\mathbf{S}$ et al. Use of mental health-related services among immigrant and US-born Asian Americans: results from the National Latino and Asian American Study. Am J Pub Health. 2007;29:91-8.

13. Spencer M, Chen J. Effect of discrimination on mental health service utilization among Chinese Americans. Am J of Pub Health. 2004;94:809-14.

14. California Health Interview Survey. CHIS 2001 Methodological series: Report 1-Sample design. Los Angeles, CA: UCLA Center for Health Policy Research, 2002.

15. California Health Interview Survey. CHIS 2001 Adult Public Use File, Release 1 [computer file]. Los Angeles, CA: UCLA Center for Health Policy Research, 2002.

16. California Health Interview Survey, CHIS 2001 Methodological series: Report 4-Response Rates. Los Angeles, CA: UCLA Center for Health Policy Research, 2003.

17. Ponce N, Ku L, Cunningham W. Language attributes and older adults: implications for Medicaid policy. Presentation at Academy Health Annual Research Meeting. San Diego, CA, 2004.

18. Jacobs EA, Karavolos K, Rathouz PJ, Ferris TG, Powell LH. Limited English proficiency and breast and cervical cancer screening in a multiethnic population. Am J Pub Health. 2005;25:1410-6.

19. Stata 9. Stata Corp, College Station, Tx, 2005.

20. California Health Interview Survey. CHIS 2001 Methodology Series: Report 5-Weighting and Variance Estimation. Los Angeles, CA: UCLA Center for Health Policy Research, 2002.

21. Bloom JR, Maslan M, Keeler C, Wallace N, Snowden LR. Overcoming language barriers to public mental health services in California. Report to the California Program on Access to Care. 2005. Accessed on July 13, 2007: http://www.ucop.edu/cpac/documents/mhservicebarriers.pdf.

22. National Archives and Records Administration. Title VI, Prohibition against national origin discrimination affecting limited English proficiency patients. Guidance to Federal financial assistance recipients regarding Title VI. Final Guidance. Federal Register: January 12, 2004. 1763-1768. Accessed online on July 30, 2007: http://archives.gov/eeo/laws/title-vi.html. 